\title{
Strength and Stiffness of Cross Laminated Timber (CLT) panels produced with \\ Pinus and Eucalyptus: experimental and analytical comparisons
}

Marcos Cesar de Moraes Pereira ${ }^{1}$, Carlito Calil Junior ${ }^{2}$

\footnotetext{
${ }^{1}$ Department of Materials and Manufacture, SMM/EESC/USP, CEP: 13566-590, São Carlos, São Paulo, Brasil. e-mail: marcoscesar@sc.usp.br

${ }^{2}$ LaMEM - Lab. Madeiras e Estruturas de Madeira, Department of Structural Engineering, SET/EESC/USP, CEP: 13566-590, São Carlos, São Paulo, Brasil.

e-mail: calil@sc.usp.br
}

\begin{abstract}
The CLT is a building material that comes mainly used in Europe where it was developed. Lightweight, sturdy and eco-friendly, this material has become one of the most important constructive methods in the world. CLT are panels formed by layers of wood glued to each other orthogonally, always in odd numbers, symmetrical with respect to the central layer. The dimensions can vary from 50 to $500 \mathrm{~mm}$ in thickness, and depend on the application, which can be a slab or wall element, the width and length are adjustable, being able to produce up to 20 meters in length. This work presents tests and results obtained in two types of CLT panels produced in a laboratory. One panel made with Pinus taeda and MUF (melamine urea formaldehyde) adhesive and other one made Eucalyptus urograndis with PU (polyurethane) adhesive. The objective was to evaluate the stiffness and to through the analytical method using the Analytical Design Method ( $\gamma$-method), and through experimental tests in the laboratory, comparing the values obtained in each method. In the experimental test, the Eucalyptus panel obtained better strength and stiffness than Pinus panel, and in analytical calculation using the Analytical Design Method ( $\gamma$-method), obtained Elastic Modulus (MOE) values slightly above experimental values, and stiffness values (EI) considerably below experimental values. Concluded that the Cross Laminated Timber produced with Pinus and Eucalyptus planted in Brazil obtained resistance and stiffness considered suitable for structural use and showed that it could be a new alternative of constructive material to be used in the country.
\end{abstract}

Keywords: CLT, Cross Laminated Timber, Timber, Wood, Structural Materials

\section{INTRODUCTION}

In the last ten years, the use of wood in the construction of houses and buildings has experienced a revolution, and of interest in the use of this material has been increasing, especially in countries that already have the culture of wood used as a structural element. The main factor that propelled the wood as a construction material to face the concrete and metallic structures was the development of constructive systems that use solid wood panels as a structural element. The first and most important cross-laminating systems are Cross Laminated Timber, CLT. According CRESPELL and GAGNON [1], the Cross Laminated Timber are panels formed by layers of wood glued to each other orthogonally, always in odd numbers, symmetrical with respect to the central layer. The dimensions can vary from 50 to $500 \mathrm{~mm}$ in thickness, and depend on the application, which can be a slab or wall element, the width and length are adjustable, being able to produce up to 20 meters in length [2]. For BRANDNER et al. [3], the CLT has become a well-known engineered timber product of global interest. The orthogonal, laminar structure allows its application as a full-size wall and floor element as well as a linear timber member, able to bear loads in- and out-of-plane. LEHMANN [4], considers CLT not just a 'product', but it's a building system and is increasingly used in Europe as an alternative to steel and concrete. Figure 1 shows a schematic of the panel, and figure 2 presents pictures of practical applications of the system. 


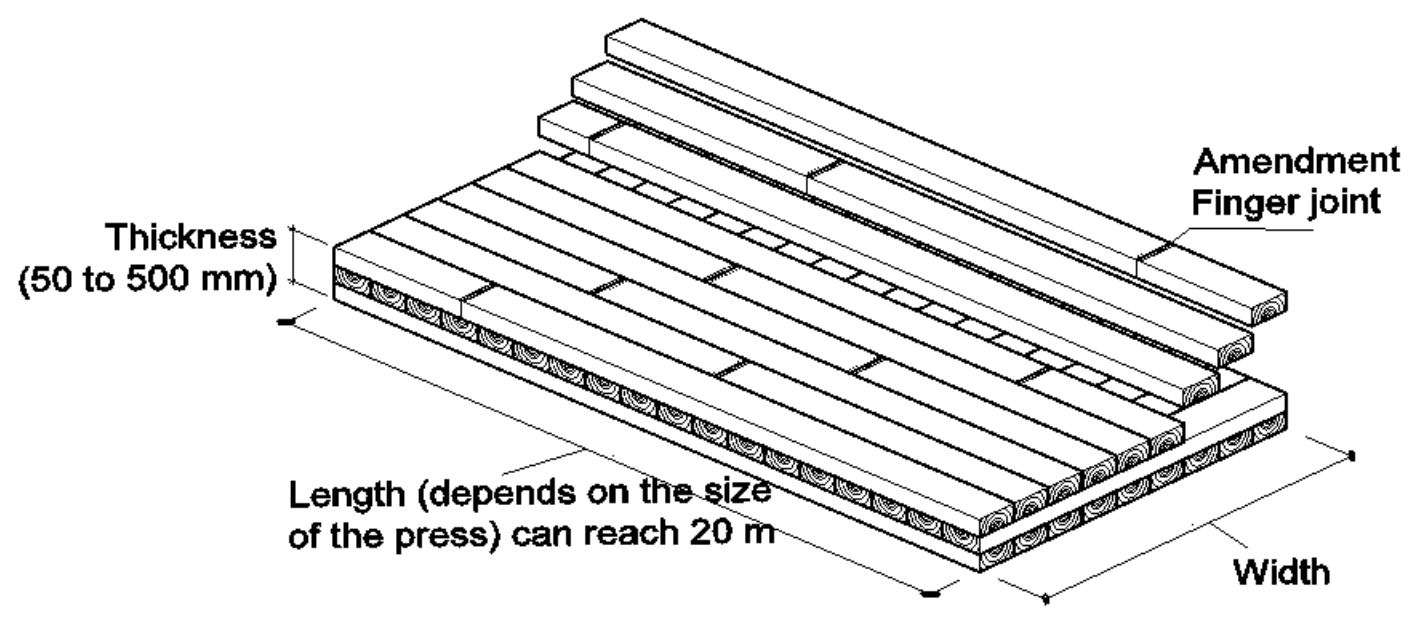

Figure 1: CLT panel model. Source: Author

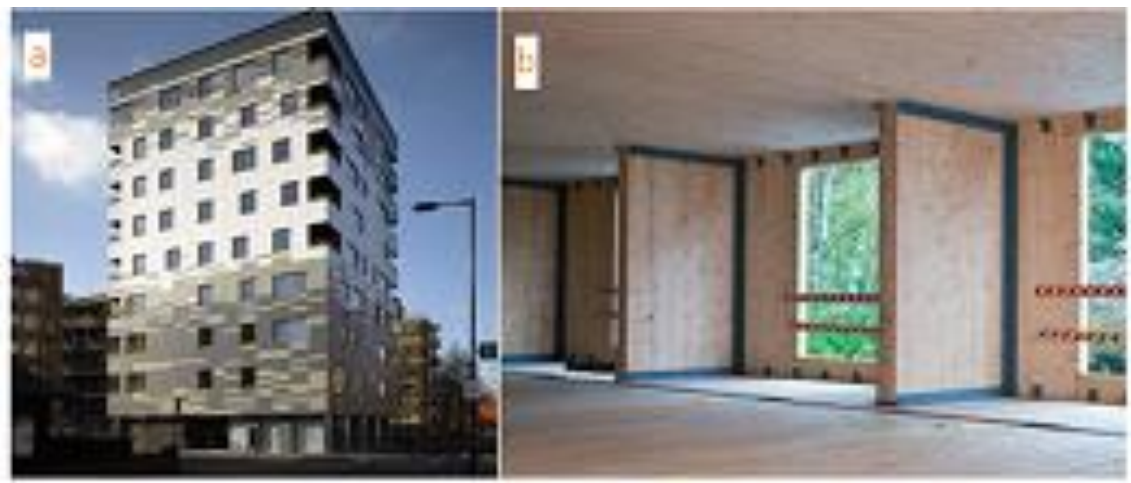

Figure 2: (a)‘Stadthaus’ building and (b) Whitmore Road; Both in London, UK. Source: LEHMANN [4]

\section{THEORETICAL REFERENCE}

\subsection{CLT advantages}

Santoni et al., [5] emphasize out points in which CLT is advantageous, such as high strength, good structural stability, fulfilment of safety requirements together with the cost competitiveness and the possibility to quickly assemble prefabricated panels, beyond to be alternative to traditional building construction materials such as concrete, masonry, and steel. On the other hand, the authors also point out that one of the disadvantages is due to their high stiffness combined with their low density, CLT structures do not provide satisfactory noise reduction.

One of the main advantages of the CLT construction system is its environmental character. These prefabricated engineered solid wood panel construction systems sequester and stock $\mathrm{CO}_{2}$ (timber acts as a carbon sink through conversion of $\mathrm{CO}_{2}$ to biomass in the process of bio-sequestration via photosynthesis) [4]. MAHALLE, et. al. [6] determined some environmental characteristics of CLT compared to reinforced concrete, based on the Life Cycle Analysis (LCA) available for Canadian Laminated Wood. The work compared the impact per square meter of the CLT slab versus an armed concrete slab, in Vancouver, Canada. The results are shown in figure 3. 


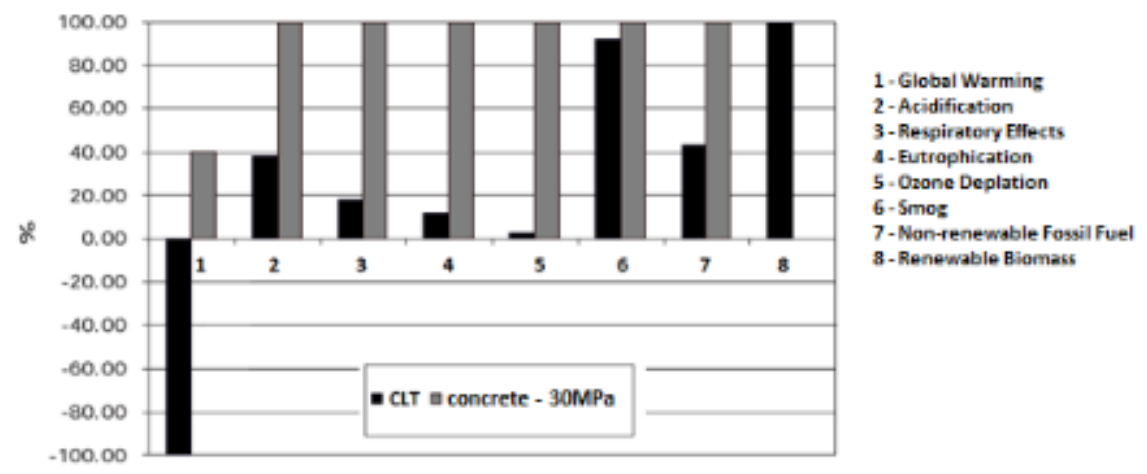

Figure 3: Comparison of ACV of $1 \mathrm{~m}^{2}$ of concrete floor versus $1 \mathrm{~m}^{2}$ of floor of CLT. Source: Adapted of MAHALLE, et al. [6]

Another advantage is with respect to the use of lower grade woods because it is a panel with redundancy, it is possible to classify visually and mechanically the lamellae, and to use the lower classes in the central lines, where the effect of the tension and compression are smaller.

CHRISTOVASILIS et al., [7] points out that the mechanical behavior of the CLT panels is complex, mainly due to the orthogonality in the direction of the successive layer grain and the inherent anisotropy of the wood, and that usually the situations where perpendicular loads to the plane of the panel are applied. For example, vertical or wind loads on floor or wall panels, or even loads in the vertical plane, which is the case of loads on walls or when the CLT is used as a beam, where the sheer will be critical.

\subsection{Analytical design method for CLT panels loaded out-of-plane}

According to AUGUSTIN [8], the complex load carrying behavior of the cross-oriented layers is in practical verifications of engineers in general reduced to a simple shear verification problem of a beam, therefore the used design models are based on homogeneous single layers, which are represented, by their thickness, stiffness and strength properties. The behavior of the normal and shear stresses are shown in figure 4 .

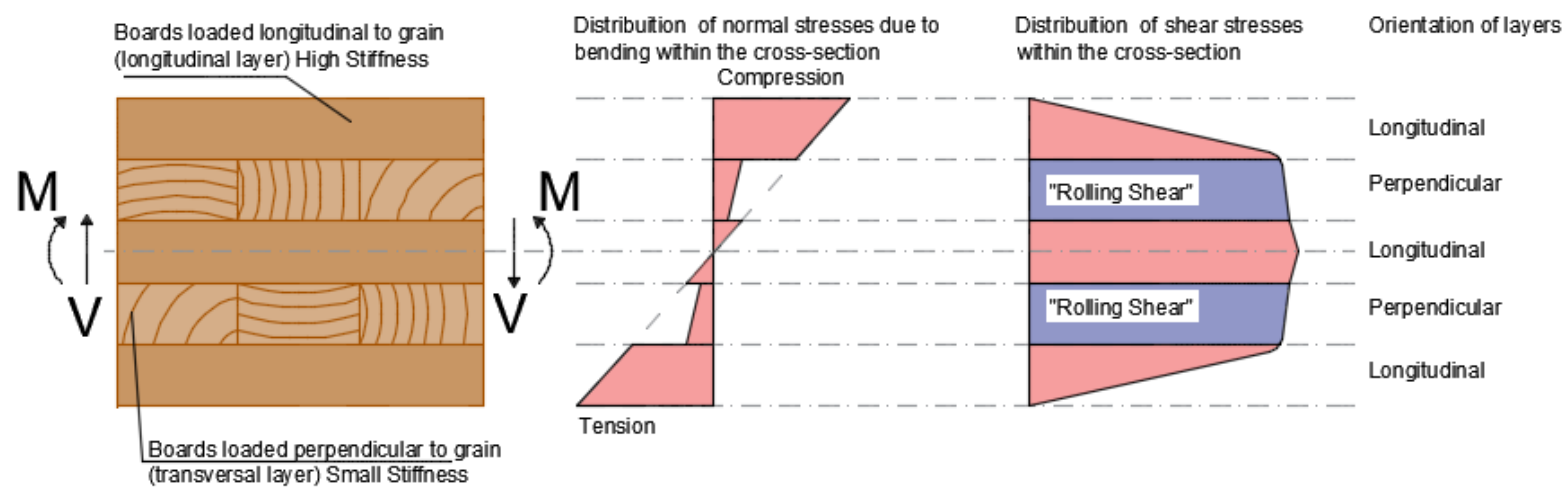

Figure 4: Stress distributions of a CLT panel loaded by a moment and a transversal force. Source: Author, adapted of AUGUSTIN, [8]

The most commonly used method for theoretically resistance analysis of CLT panels is the Mechanically Jointed Beams, also called the Gamma Method ( $\gamma$-method). KREUZINGER [9] explains that this method is used for situations where there are at least two or more components that are individual joined either by mechanical fasteners or by interim layers with comparatively low shear stiffness. In this case, the Bernoulli hypothesis and consequently the Euller-Bernoulli beam theory does not apply because of relative displacements between the different beam parts and the connectors being semi-rigid (nails, screws, and bolts). Figure 5 shows the Mechanically Joined Beams ( $\gamma$-method) for a T-beam. 


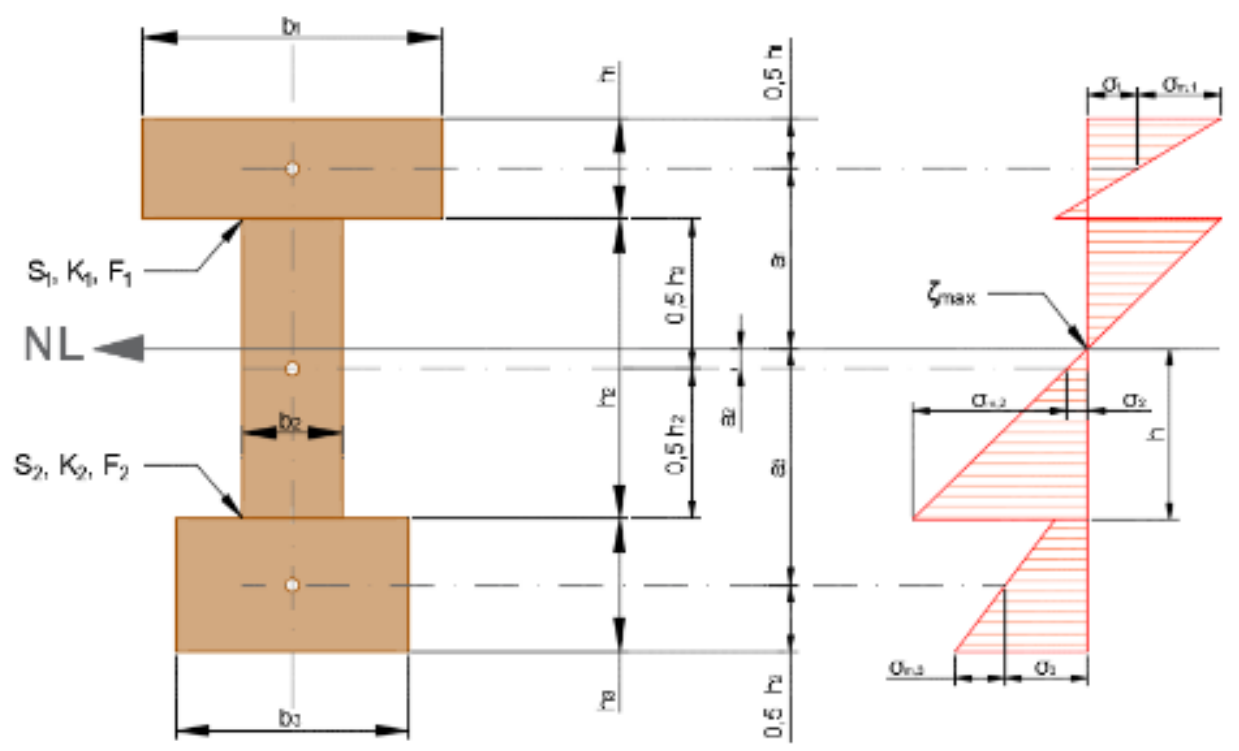

Figure 5: Cross-section for T-beam (left) and distribution of bending stresses (right). Source: Author (adapted from Annex B of Eurocode 5, [10])

In figure 5, the symbols $\mathrm{S}$ means spacing in between connectors, $\mathrm{K}$ means the slip module of connection $\left(\mathrm{k}_{\mathrm{ser}}\right)$, F means the load applied in each element, NL is neutral line, and the small circles point to the centroids of each element of the beam.

The $\gamma$-method was developed by Professor Karl Möhler in 1956, for beams joined with mechanical connectors, and for use in bi-supported cases. However, boundary conditions and adaptations make the gamma method currently the simplest way to calculate CLT slabs. Other more precise methods have been developed, such as the Shear Analogy Method, also called Kreuzinger Method, but are more complex and require to use of computer software (plane frame analysis programs), which can consider shear deformations in bar elements [9].

GAGNON E POPOVSKI [11] summarize this topic explaining that $\gamma$-method is an efficiency factor that aims to reduce the effective inertia of the cross-section of the element depending on the slip module of the connection between the pieces of wood (kser). The rolling shear module replaces the slip module in the case of the CLT, where the layers are glued. The authors explain that if assume that only boards oriented in the longitudinal direction are carrying the load, then we can take into account the rolling shear stiffness (or deformability) of the cross layers as stiffness (or deformation) caused by "imaginary fasteners" connecting the longitudinal layers [11].

That is, the central layer works as a connector (nail, screw or dowel), and is calculated the gamma factor replacing in the equation the component concerning to the slip of the connector $\left(\mathrm{k}_{\mathrm{ser}}\right)$ by the module of the rolling shear. Usually, the gamma factor is a number that lies between 0 and 1 , where 1 is the value obtained for totally rigid connections, as is the case of connections made with adhesives. Thus, the adhesive bonding between the layers does not interfere with the calculation of the gamma factor, which only considers the transverse layer as a "connector" between the longitudinal layers. A scheme is shown in figure 6 to illustrate the effect of rolling shear. 


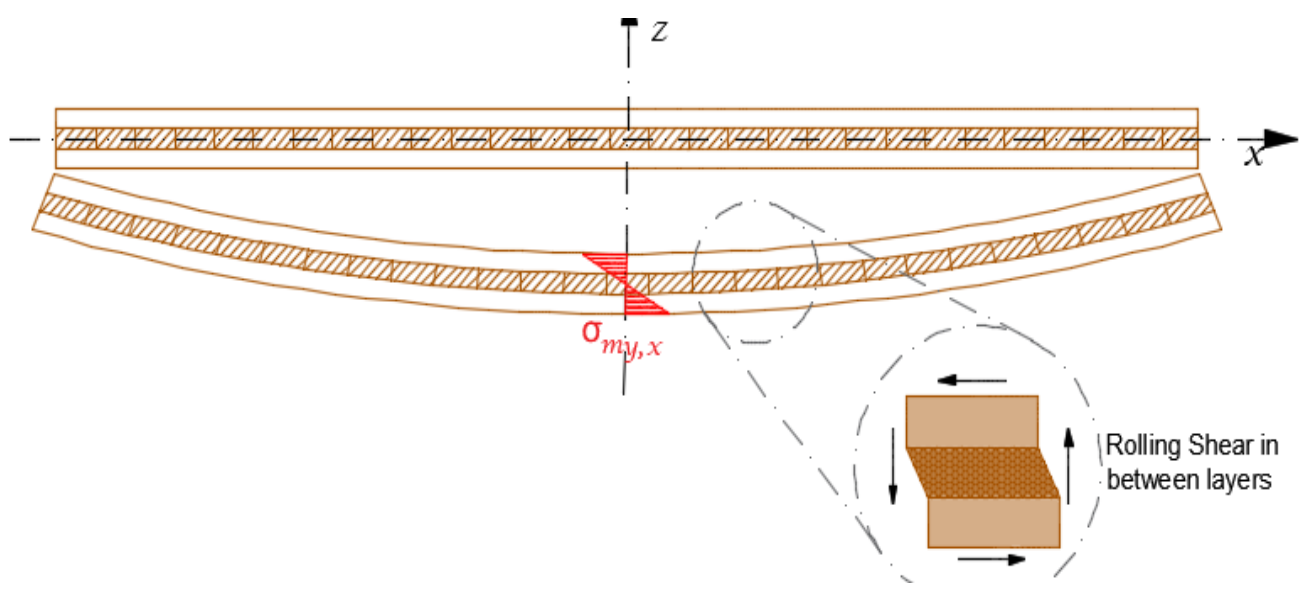

Figure 6: Rolling shear effect for a linear load for a bi-supported panel. Source: Author

For GAGNON E POPOVSKI [11] the symbol that represents the rolling shear module is $\mathrm{G}_{\mathrm{R}}\left(\mathrm{N} / \mathrm{mm}^{2}\right)$. For the American and Canadian Standard ANSI APA PRG 320 [12], rolling shear is defined as $\mathrm{G}_{90}\left(\mathrm{~N} / \mathrm{mm}^{2}\right)$. The latest standard on CLT is Eurocode EN 16351 [13], which defines rolling shear stiffness as $\mathrm{G}_{9090 \text {,lay }}$ $\left(\mathrm{N} / \mathrm{mm}^{2}\right)$, and rolling shear strength as $f_{v, 9090},\left(N / \mathrm{mm}^{2}\right)$ the resistance to rolling shear as $R_{v, z x, x l a m}$ or $R_{v, y z, x l a m}$ (Nmm). Figure 7 shows the details of the forces acting on the CLT panel for linear loads, with symbols defined by the European standard.

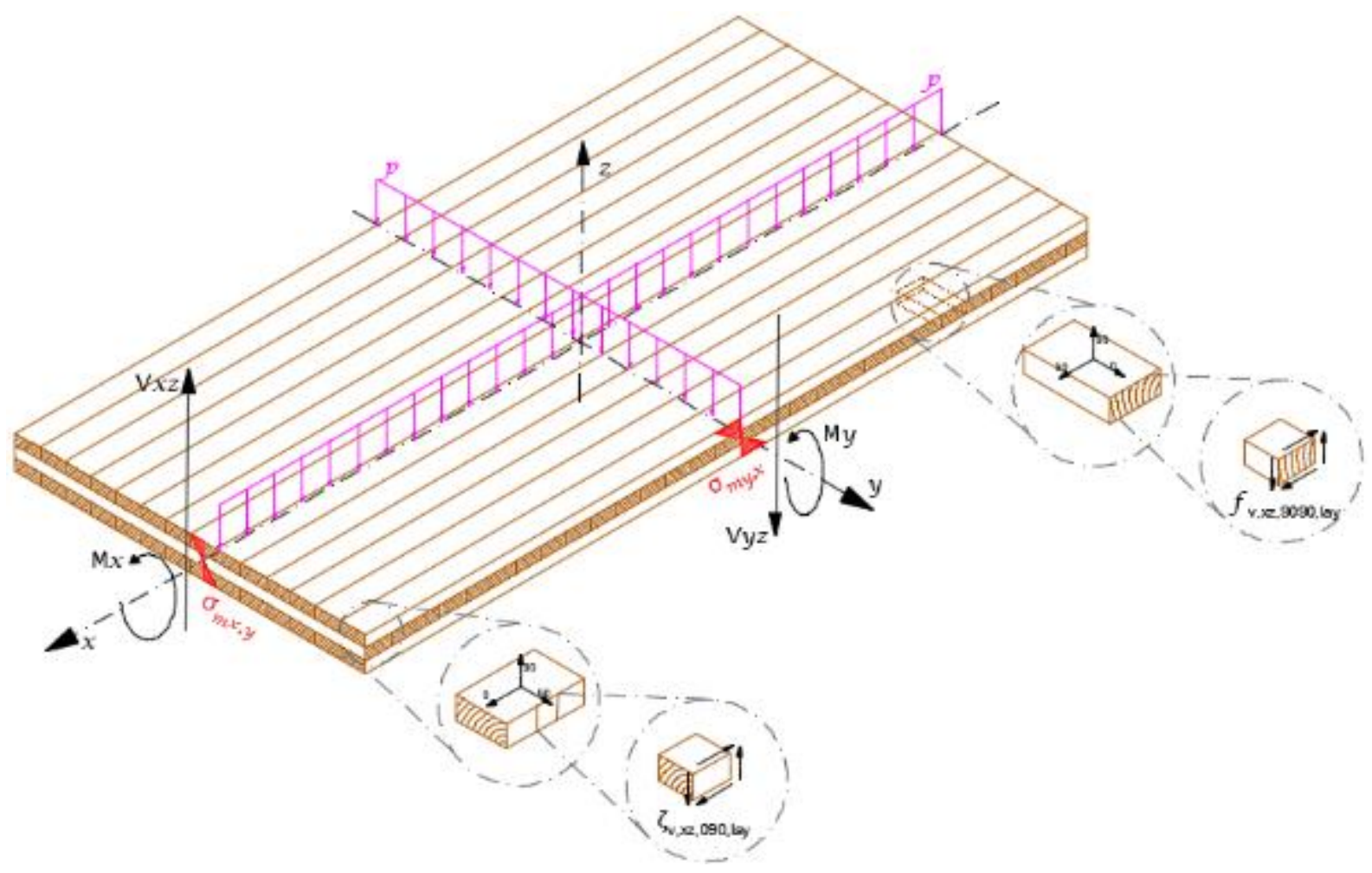

Figure 7: Rolling shear effect for a linear load of a bi-supported panel. Source: Author (adapted from Annex F of EN $16351[13])$

Both the European and the North American standard define the value of the rolling shear as $10 \%$ of the value of the shear modulus parallel to the grain of the boards (i.e.), $G_{90}$ is $0.1 \cdot G_{0}$. That is, the equation defining the gamma coefficient (equation 1), present in Annex B of Eurocode 5 [10], has the component relative to the slip module replaced by the component relative to the rolling shear (equation 2 ). 
$\gamma_{i}=\frac{1}{\left[1+\frac{\pi^{2} \cdot E_{i} \cdot A_{i} \cdot S_{i}}{K_{i} \cdot L^{2}}\right]}$

Where:

$E_{i}$ modulus of elasticity of each cross-sectional element;

$A_{i}$ area of each part of the cross section;

$S_{i}$ spacing of the nails at the interface of element i with element 2;

$K_{i}$ slip module of the connection of element $i$ with element 2 ;

$L$ effective span of the beam ( $\mathrm{L}=$ span, for bi supported beams), $(\mathrm{L}=0.8 \times$ span, for continuous beams) and ( $\mathrm{L}=2 \times$ span, for swing beams).

$$
\gamma_{i}=\frac{1}{1+\left[\frac{\pi^{2} \cdot E_{i} \cdot A_{i}}{L^{2}} \cdot \frac{\bar{h}}{G_{90} \cdot b}\right]}
$$

Where:

$h$ thickness of the CLT cross-layers;

$G_{90}$ rolling shear stiffness modulus;

$b$ total thickness of the CLT slab.

Based in Euler- Bernoulli beam theory, the Annex B to Eurocode 5 also defines that the effective bending stiffness should be taken as present in equation 3 where the coefficient gamma denotes a value between 0 and 1 , by which the Steiner parts $\left(\mathrm{E}_{\mathrm{i}} \cdot \mathrm{A}_{\mathrm{i}} \cdot \mathrm{a}_{\mathrm{i}}{ }^{2}\right)$ of bending stiffness contributions of the individual components within the total cross section are reduced [9].

$(E I)_{e f}=\sum_{i=1}^{3}\left(E_{i} I_{i}+\gamma_{i} E_{i} A_{i} a_{i}^{2}\right)$

Where:

$a$ distance from the center of each layer to the center of the panel;

$A$ area of the cross section;

$I$ moment of inertia;

$E$ elasticity module.

The parameters $a$ and $h$ are shown in figure 8 .

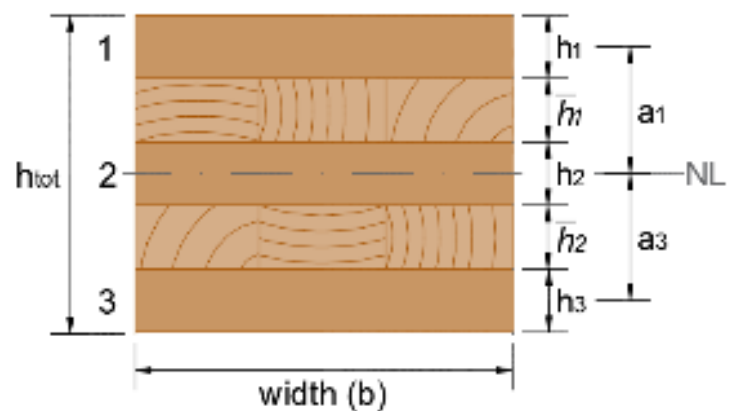

Figure 8: Geometric characteristics for $\gamma$-method. Source: Author (adapted from GAGNON AND POPOVSKI [11])

If the modulus of elasticity and the thickness of the layers are equal, equation 3 can be simplified for 
equation 4 for five layers, or equation 5 for three layers, with $\mathrm{a}_{2}=0$.

$(E I)_{e f}=E I\left[3+\frac{2 \gamma A a^{2}}{I}\right]$

$(E I)_{e f}=2 E\left(I+\gamma A a^{2}\right)$

If the modulus of elasticity and thickness of layers are not equal, factor $a_{2}$ should be calculated for equation 6.

$a_{2}=\frac{\gamma_{1} E_{1} A_{1}\left(\frac{h_{1}}{2}+\overline{h_{1}}+\frac{h_{2}}{2}\right)-\gamma_{3} E_{3} A_{3}\left(\frac{h_{2}}{2}+\overline{h_{2}}+\frac{h_{3}}{2}\right)}{\sum_{i=1}^{3}\left(\gamma_{i} E_{i} A_{i}\right)}$

It is observed that for use of the gamma method, shear deformations of the individual components are negligible, (i.e.), b/h ratio of the panel must be greater than 20 and the span to be large.

BLAß AND SANDHAAS [14] demonstrated that the overall stress for the case of the $\gamma$-method in semi-rigid connections is calculated through equation 7 .

$\sigma=\frac{M}{I_{e f}} \cdot\left(\frac{h_{1}}{2}+\gamma_{1} a_{1}\right)$

The same authors point out that all internal forces and moments transferred through a semi-rigid joint must be reduced by the coefficient, including shear stresses [14].

From the EI stiffness of the CLT panel, the maximum deflection can be estimated by calculating the maximum load, based on the serviceability limit states. Usually the use of the panels as floor element are for distributed loads, as is the case of homes, offices or commercial buildings. The Brazilian standard NBR $6120 / 1980$ [15] establishes the loading limits for each case, being for residential use 150 a $200 \mathrm{Kgf} / \mathrm{m}^{2}$. The deflection for distributed loads is present in equation 8 .

$w=\frac{5}{384} \cdot \frac{p l^{4}}{E I}$

Where:

$w$ deflection;

$p$ is distributed load;

$l$ span.

Considering that in the elastic phase of the panel in deflection, the deflection can be limited by a relation with the size of the span. These limits (y) are located between 100 and 500, that is, deflection $w=l / y$. Starting from this relation, it is estimated the maximum load to be applied in the CLT for various spans, through equation 9.

$$
\begin{aligned}
& w=\frac{l}{y}=\frac{5}{384} \cdot \frac{p l^{4}}{E I_{e f}} \\
& \therefore \quad p=\frac{384 E I_{e f}}{5 y l^{3}}
\end{aligned}
$$




\subsection{CLT in Brazil}

The interest in the use of engineered wood products, mainly the Glulam beams, has been increasing in the Brazilian market, which currently has four factories of Glulam [16]. The use of the CLT panels is not yet a reality in Brazil, largely due to the lack of knowledge about the material and the construction system, but there is already an industry producing panels in São Paulo State.

The development of projects that use CLT by engineers and architects can encourage the use of this product in the country. Currently Brazil have a great potential of production and use, because today the country currently has 2 million hectares of Pinus forests and 7.4 million hectares of Eucalyptus forest [17].

Some researchers in the country are developing projects and testing, in initial phases. This work presents tests and results obtained in two types of CLT panels produced in a laboratory. One panel made with Pinus taeda and MUF (melamine urea formaldehyde) adhesive and other one made Eucalyptus urograndis with PU (polyurethane) adhesive. The objective was to evaluate the stiffness and to through the analytical method using the Analytical Design Method ( $\gamma$-method), and through experimental tests in the laboratory, comparing the values obtained in each method.

\section{MATERIALS AND METHODS}

\subsection{Materials}

The analysis were made in two panels with characteristics present in table 1 .

Table 1: Characteristics of CLT panels

\begin{tabular}{|c|c|c|c|c|c|c|c|c|c|c|}
\hline \multirow[b]{2}{*}{ Cod. } & \multirow[b]{2}{*}{ Wood } & \multirow[b]{2}{*}{ Adhesive $^{1}$} & \multicolumn{6}{|c|}{ Layup (mm) } & \multirow{2}{*}{$\begin{array}{c}\text { Dimension } \\
(\mathrm{L} \times \mathrm{b} \times \mathrm{h}) \\
(\mathrm{mm})\end{array}$} & \multirow{2}{*}{$\begin{array}{l}\text { Press }^{2} \\
(\mathrm{MPa})\end{array}$} \\
\hline & & & Num. & $=$ & $\perp$ & $=$ & $\perp$ & $=$ & & \\
\hline Panel A & Pinus taeda & MUF & 5 layers & 16 & 16 & 16 & 16 & 16 & $2115 \times 1400 \times 80$ & 0,7 \\
\hline Panel B & $\begin{array}{l}\text { Eucalyptus } \\
\text { Urograndis }\end{array}$ & PU & 3 layers & 32 & 32 & 32 & - & - & $2600 \times 1200 \times 96$ & 0.9 \\
\hline
\end{tabular}

${ }^{1}$ The adhesives were two types:

MUF - Melamine-urea Formaldehyde, bi-component, made for Akzo Nobel.

PU - Polyurethane mono-component, made for Jowat, model 686.60.

${ }^{2}$ The press type was a hydraulic press, with 0,7 to $1 \mathrm{MPa}$, as recommended by the adhesive manufacturer.

For the production of the panels, a hydraulic press was made by Becker and Van Kumer, belonging to Serraria Ibaiti. The adhesives were applied with the use of a brush, obeying the amount per square meter (weight) recommended by each manufacturer. The pressing time was 15 hours for both panels, with 0,7 MPa $\left(7 \mathrm{kgf} / \mathrm{cm}^{2}\right)$ e $0,9 \mathrm{MPa}\left(9 \mathrm{kgf} / \mathrm{cm}^{2}\right)$. The manufacture of the panels is shown in figure 9 and 10 .
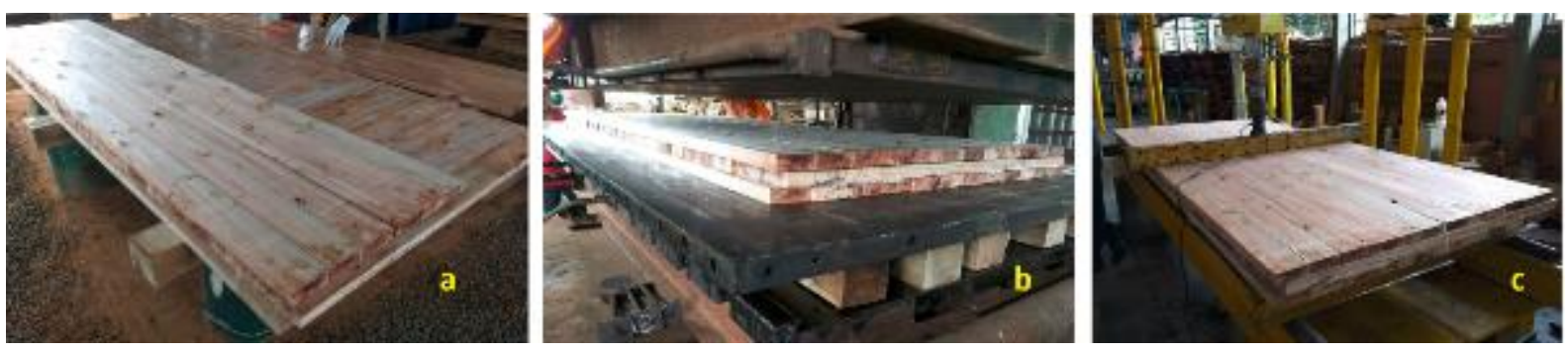

Figure 9: Manufacture of Eucalyptus CLT panel, a) assembly and application of adhesive, b) panel pressing, and c) panel finalized during bending test in laboratory. Source: Author 

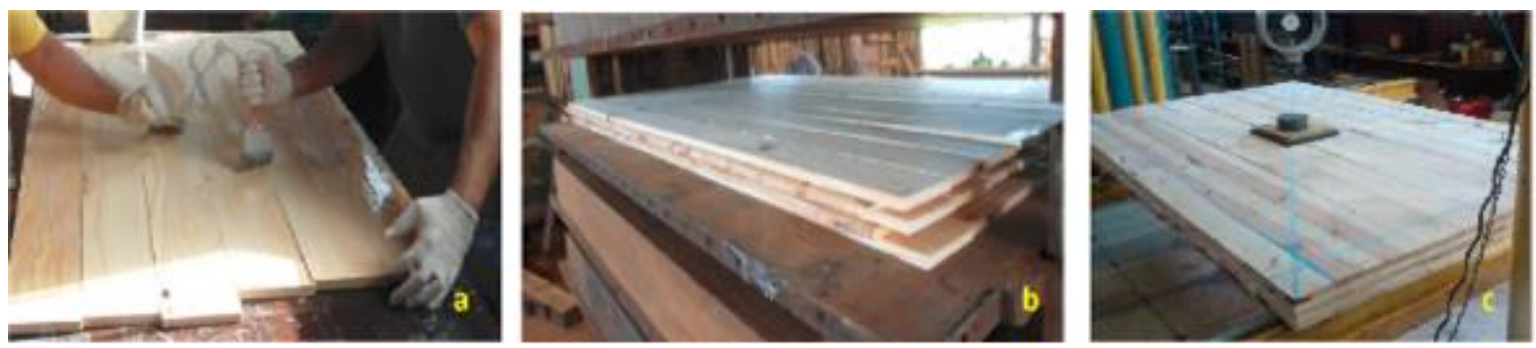

Figure 10: Manufacture of Pinus CLT panel, a) assembly and application of adhesive, b) panel pressing, and c) panel finalized before test in laboratory. Source: Author

\subsection{Methods}

\subsubsection{Experimental method}

Tests were done by applying a distributed load along the panel, in the middle of the span. They were tested in the longitudinal direction and transverse direction (figure 11) for thee times each panel. Displacement meters were positioned below the panels and the load was measured by a load cell. With the data collected in the test and the gauging values of the panel, equation 10 was applied to determine experimental stiffness ( $\left.\mathrm{EI}_{\mathrm{exp}}\right)$.

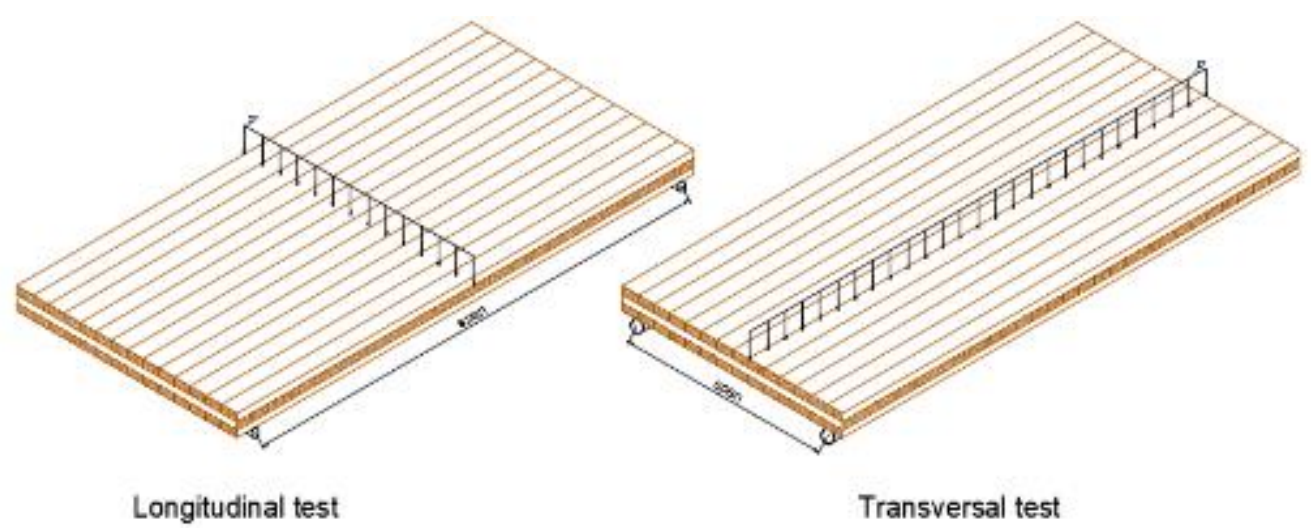

Figure 11: Test scheme for longitudinal (x) and transversal (y) directions. Source: Author

$(E I)_{\exp }=\frac{\Delta p}{\Delta \delta} \cdot \frac{L^{3}}{48}$

Where:

$L$ is span;

$p$ is load;

$\delta$ is displacement.

\subsubsection{Analytical method}

For analytical analysis was used the method described in item 2.2, Mechanically Jointed Beams, $\gamma$-method. The geometric parameters for the application of the method for each panel produced are presented in table 2 , as described in figure 8.

Table 2: Geometric parameters for calculus of $\gamma$-method

\begin{tabular}{lcccccccc}
\hline & \multicolumn{8}{c}{ GEOMETRIC PARAMETERS (MM) } \\
\cline { 2 - 9 } CLT Panel & $h_{1}$ & $h_{2}$ & $h_{3}$ & $\overline{h_{1}}$ & $\overline{h_{2}}$ & $a_{1}$ & $a_{2}$ & $a_{3}$ \\
\hline Pinus & 16 & 16 & 16 & 16 & 16 & 32 & 0 & 32 \\
Eucalyptus & 32 & 32 & - & 32 & - & 32 & 5,47 & 32 \\
\hline
\end{tabular}




\section{RESULTS AND DISCUSSION}

For the bending test in the longitudinal direction, figure 12 shows the force versus displacement for each panel. For each panel, three loading cycles were made. It is possible to note that the panel of Eucalyptus deform less than the panel of Pinus, showing that it has greater stiffness.

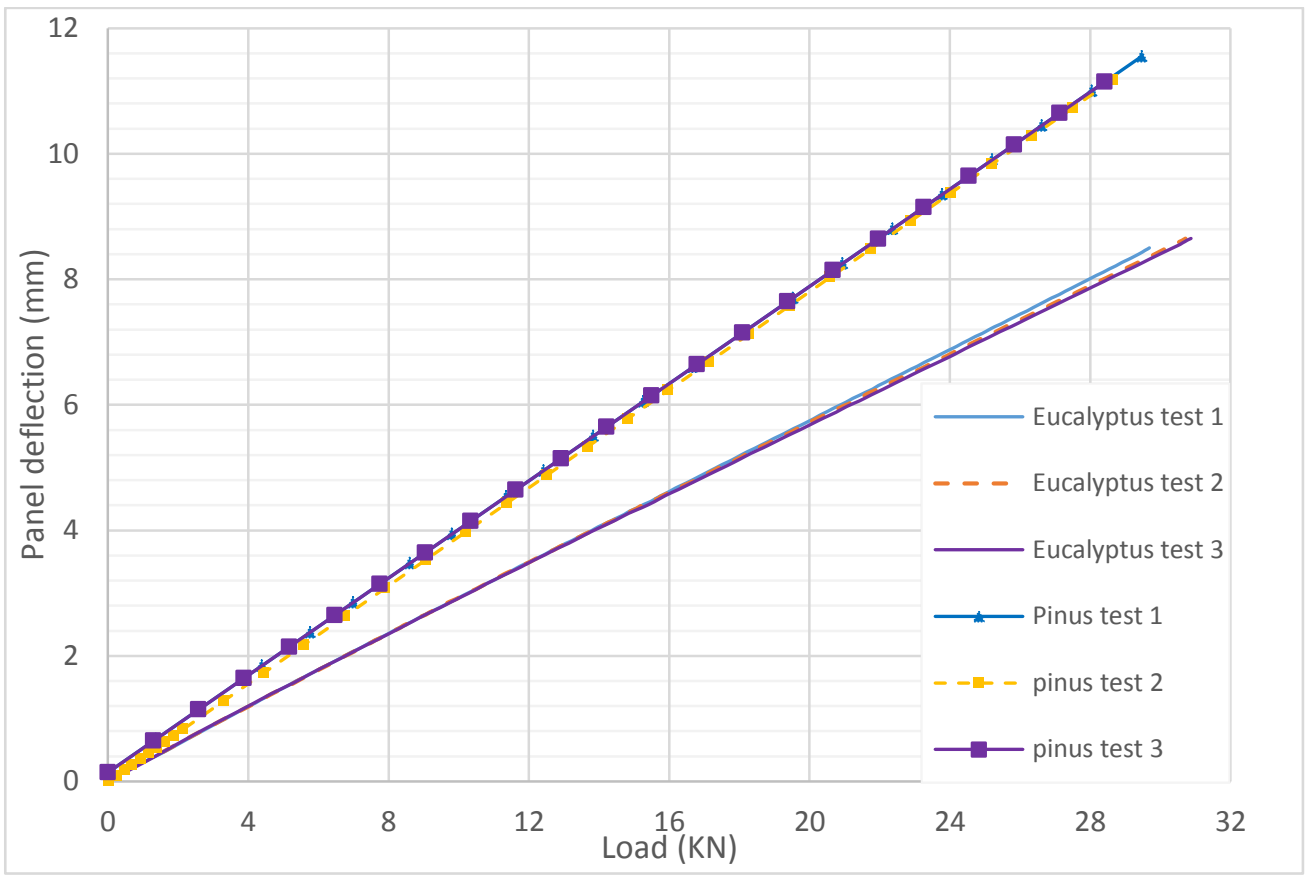

Figure 12: Deflection versus load for longitudinal test

For the bending test in the transversal direction, figure 13 shows the force versus displacement relationship, but it is possible to note that both panels had similar results. Possibly the result of the transverse flexion was affected by the shear effect, since the L/h ratio (Span/ height) for both cases was lower than 20 . According to Gagnon and Popovski [11], the span-to-depth must be at least 20, but the authors mention that in the literature there are papers that defend the thesis that this ratio should be 30 .

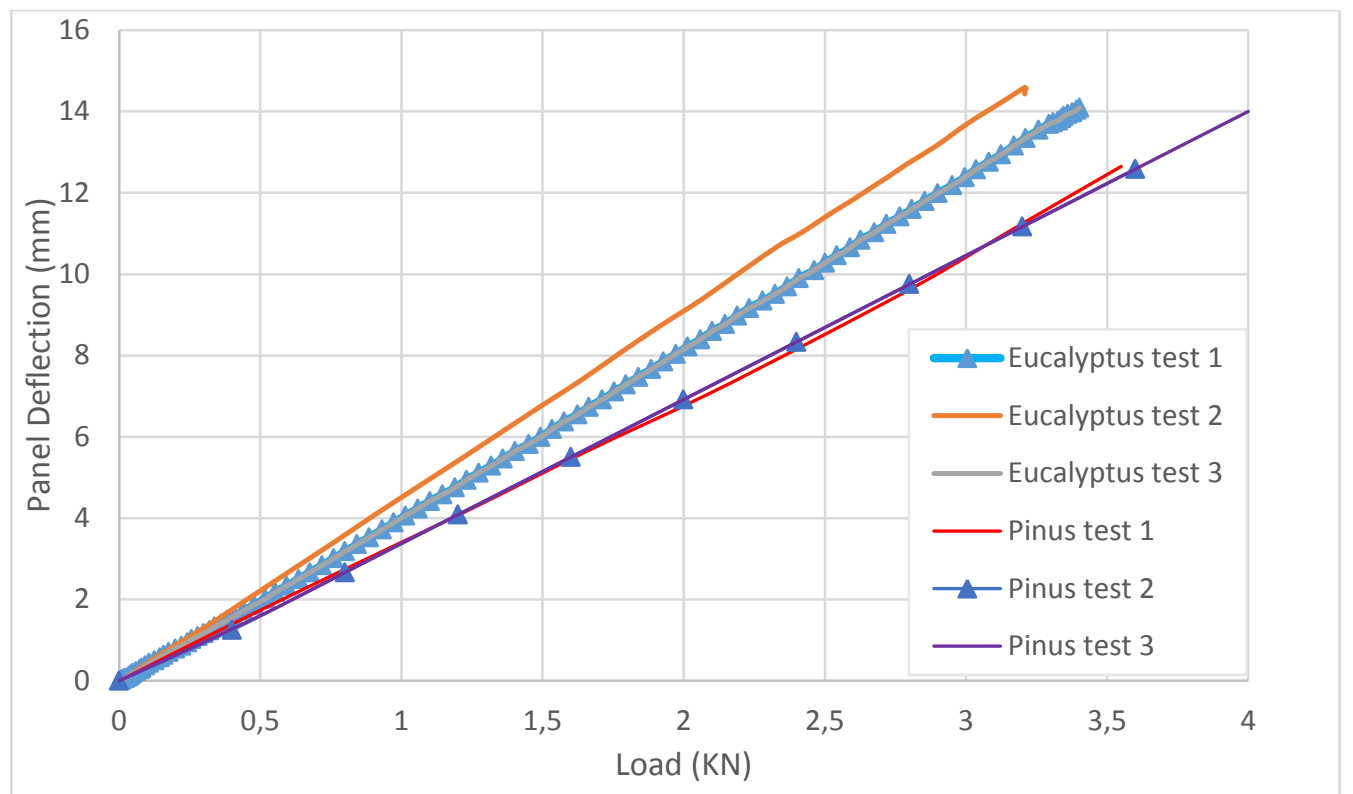

Figure 13: Deflection versus load for transversal test

Figures 14 and 15 show curves showing the stiffness of the panel in relation to the load distributed per 
$\mathrm{m}^{2}$ versus the free span of the panel, for use as a floor element in a residence for example. This comparison presents 5 deflection criteria (L/100, L/200, .., L/500), calculated from the gamma method and by equation 9. It also follows the experimental curve that was based on data obtained from the flexural test two panels manufactured.

Tables 3 and 4 show the analytical values calculated by the gamma method and the values obtained in the bending tests of the panels manufactured. It is noted that the experimental stiffness (EI) for both panels was greater than the analytical stiffness. This is evident in the graphs of Figures 14 and 15, where the 'experimental' curve shows that in this case the panel resists more load per square meter than the other deflection criteria.

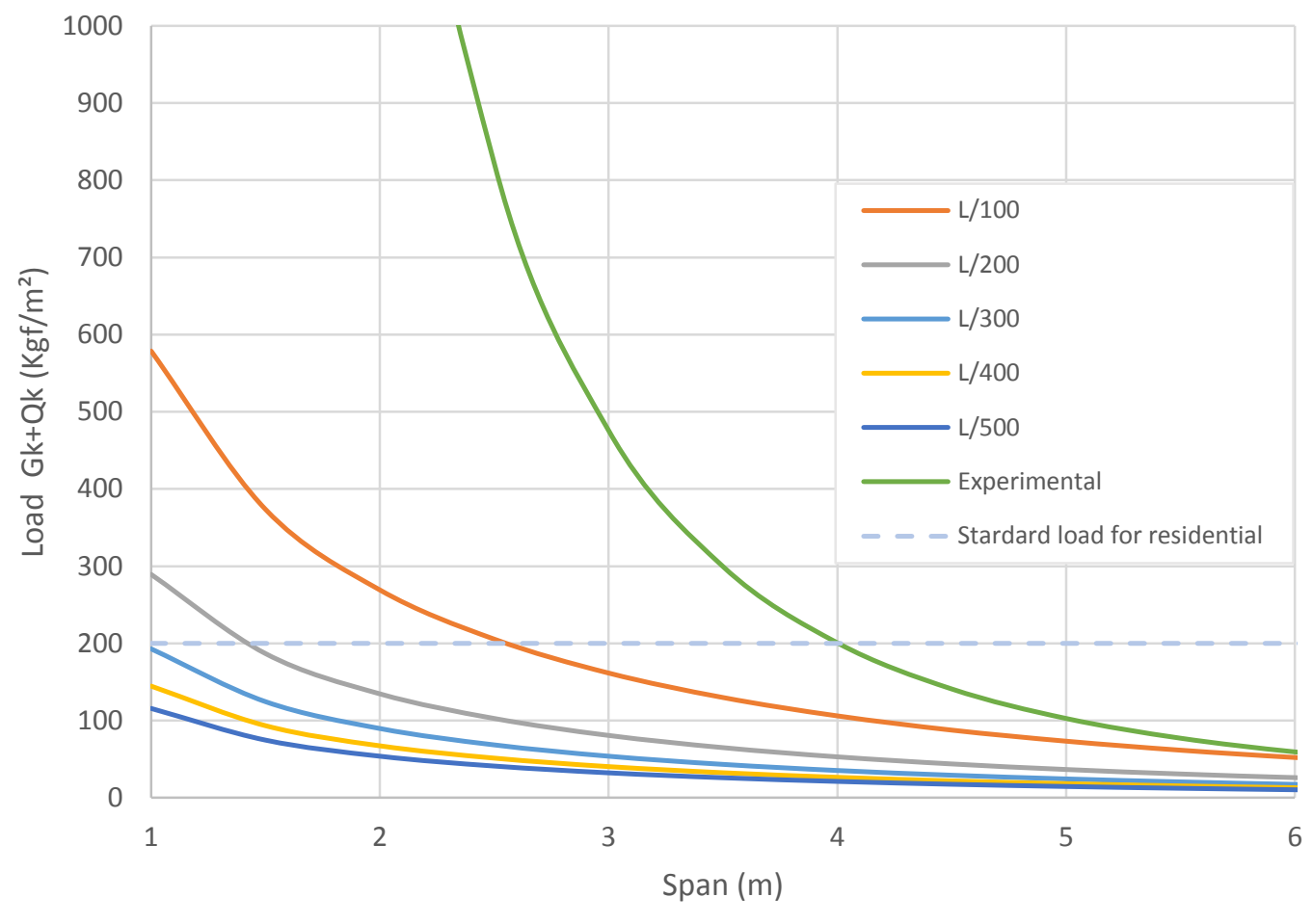

Figure 14: Variation of maximum uniformly distributed load with the span of Pinus panel for different deflection criteria 


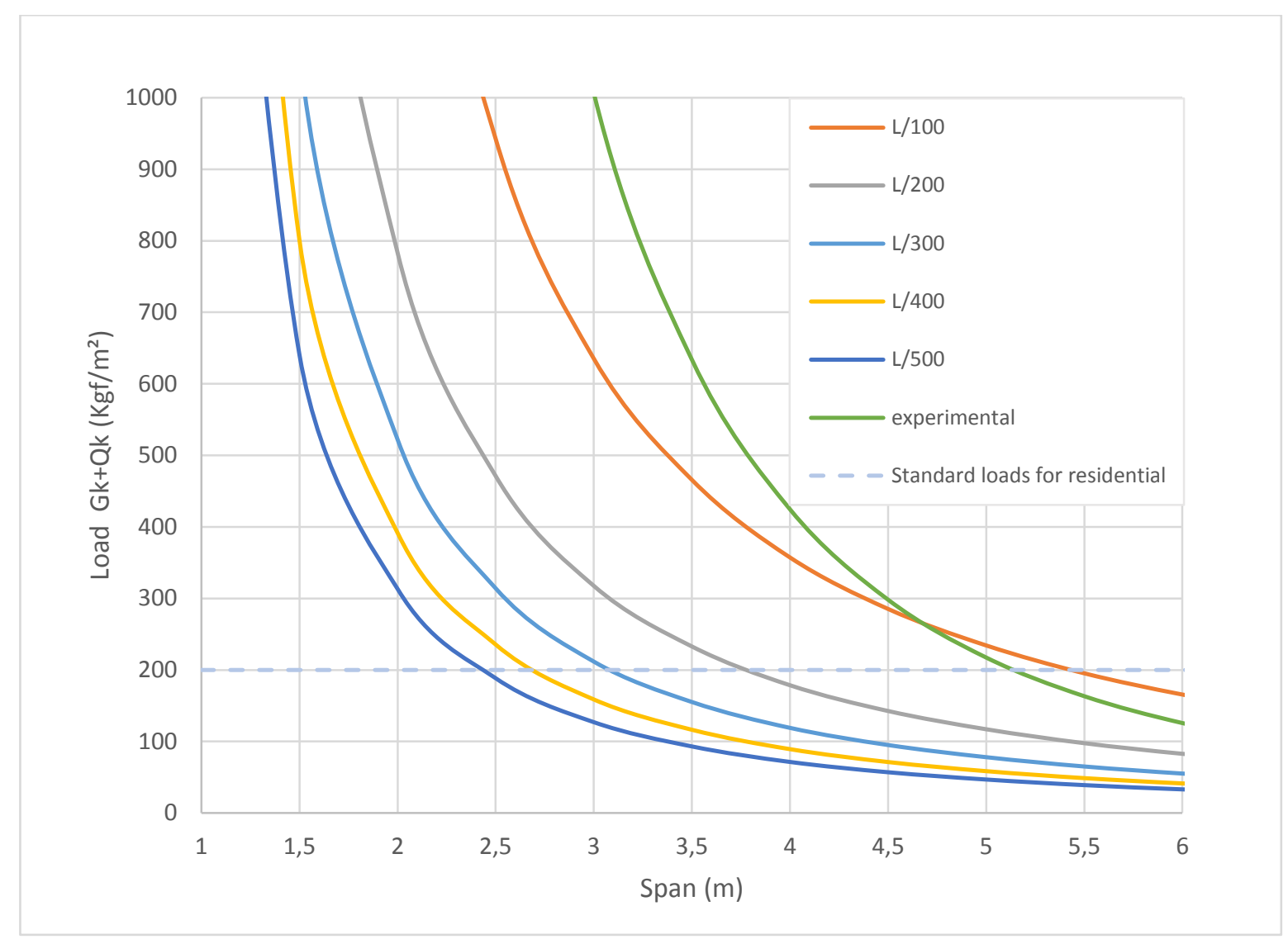

Figure 15: Variation of maximum uniformly distributed load with the span of Eucalyptus panel for different deflection criteria

Again tables 3 and 4, present the values of the Elasticity Modulus obtained experimentally and analytically. In this case the analytical elasticity modulus was higher than that obtained in the tests, with the Experimental/Analytical ratio being about $82 \%$ for the Pinus panel and $88 \%$ for the Eucalyptus panel.

Table 3: Experimental and Analytical Results for Pinus CLT's

\begin{tabular}{ccc}
\hline & $\begin{array}{c}\mathrm{E}_{\mathrm{m}} \\
(\mathrm{MPa})\end{array}$ & $\begin{array}{c}\mathrm{EI}_{\mathrm{m}} \\
\left(\mathrm{KN} \cdot \mathrm{m}^{2}\right)\end{array}$ \\
\hline Experimental & 5461 & 492 \\
Analytical & 6667 & 197 \\
\hline Ratio Exp./Analyt. $(\%)$ & 81,9 & 249,8 \\
\hline
\end{tabular}

Table 4: Experimental and Analytical Results for Eucalyptus CLT's

\begin{tabular}{ccc}
\hline & $\begin{array}{c}\mathrm{E}_{, \mathrm{m}} \\
(\mathrm{MPa})\end{array}$ & $\begin{array}{c}\mathrm{EI}_{{ }_{\mathrm{m}}} \\
\left(\mathrm{KN} \cdot \mathrm{m}^{2}\right)\end{array}$ \\
\hline Experimental & 11740 & 1030 \\
Analytical & 13275 & 871 \\
\hline Ratio Exp./Analyt. $(\%)$ & 88,4 & 118,3 \\
\hline
\end{tabular}

Table 5 shows how the inertia of the CLT panel is reduced by the calculation of the gamma method. For each panel and each span, the $\mathrm{I}_{\text {eff }} / \mathrm{I}_{\text {full }}$ relationship changes. The trend shows that the higher the span, the more $I_{\text {eff }}$ approaches $I_{\text {full. }}$. The $I_{\text {eff }}$ value is the stiffness that the panel has and must be used for the calculus of the building using the clt as constructive material. 
Table 5: relationship between values of moments of Effective Inertia and Full Inertia, for different free span.

\begin{tabular}{cc|cccc|cccc}
\hline & & \multicolumn{3}{|c|}{ I EFFECTIVE (DEPENDING ON SPAN LENGTH L) } & \multicolumn{3}{|c}{ I EFFECTIVE / I FULL } \\
\hline \multirow{2}{*}{ Panel } & $\begin{array}{c}\text { I full } \\
\left(10^{4} \mathrm{~mm}^{4}\right)\end{array}$ & $\begin{array}{c}\mathrm{L}=2000 \mathrm{~mm} \\
\left(10^{4} \mathrm{~mm}^{4}\right)\end{array}$ & $\begin{array}{c}\mathrm{L}=4000 \mathrm{~mm} \\
\left(10^{4} \mathrm{~mm}^{4}\right)\end{array}$ & $\begin{array}{c}\mathrm{L}=6000 \mathrm{~mm} \\
\left(10^{4} \mathrm{~mm}^{2}\right)\end{array}$ & $\begin{array}{c}\mathrm{L}=8000 \mathrm{~mm} \\
\left(10^{4} \mathrm{~mm}^{4}\right)\end{array}$ & $\begin{array}{c}\mathrm{L}=2000 \\
\mathrm{~mm}(\%)\end{array}$ & $\begin{array}{c}\mathrm{L}=4000 \\
\mathrm{~mm}(\%)\end{array}$ & $\begin{array}{c}\mathrm{L}=6000 \\
\mathrm{~mm}(\%)\end{array}$ & $\begin{array}{c}\mathrm{L}=8000 \\
\mathrm{~mm}(\%)\end{array}$ \\
\hline Pinus & 4266 & 2976 & 3196 & 3240 & 3256 & $70 \%$ & $75 \%$ & $76 \%$ & $76 \%$ \\
Eucalyptus & 7372,8 & 4314 & 5361 & 5624 & 5723 & $59 \%$ & $73 \%$ & $76 \%$ & $78 \%$ \\
\hline
\end{tabular}

Data refer to panel strips of $1000 \mathrm{~mm}$ wide

\section{CONCLUSIONS}

The first conclusion obtained in this study was regarding the stiffness values of the panels. Considering the CLT's produced in laboratory scale using as base material exotic wood planted in Brazil - Pinus and Eucalyptus - joined with two imported adhesives, the values of stiffness obtained were satisfactory when compared to the values obtained in similar tests published in the literature and technical materials of European manufacturers using mainly coniferous wood, like KLH Gmbh, for example [18].

In the experimental test, the Eucalyptus panel obtained better strength and stiffness, confirming the tendency already predicted, since Eucalyptus has higher physics and mechanicals properties than Pinus. Despite the natural tendency of Eucalyptus to exhibit larger drying defects after manufacture and testing, the panel did not show cracking. Pinus wood has more natural growth defects, such as large knots, which may have interfered mainly with the Modulus of Elasticity (MOE) of the Pinus panel.

The analytical calculation using the Analytical Design Method ( $\gamma$-method), obtained Elastic Modulus (MOE) values slightly above experimental values, and stiffness values (EI) considerably below experimental values. It is noted that the method is underestimating the stiffness of the material, which from the point of view of the structural design is an advantage since it is contributing to the safety of the structure. The experimental modulus of elasticity when being used in the dimensions will be reduced by the safety factors, being equal to or less than the characteristic experimental values. Figures 14 and 15 graphically present this difference, relating the loads applied to the structure per square meter to the maximum span supported by the material in the bending.

For the $\gamma$-method, one of the factors influencing the calculation is the value of the Rolling Shear, which in this study was considered as E0/160, as described in the literature. However, it is suggested for future work that specific tests be made with the Brazilian woods, to prove the relation presented, and thus adjust the $\gamma$ factor for Brazilian species.

It was also concluded that the Cross Laminated Timber produced with Pinus and Eucalyptus planted in Brazil obtained resistance and stiffness considered suitable for structural use and showed that it could be a new alternative of constructive material to be used in the country. It should be noted that in the manufacturing process of the panels the quality control must be observed, mainly referring to the pressure applied to the press during the bonding, which should be the pressure recommended by the manufacturer of the structural adhesive, usually obtained with the use of a hydraulic press.

\section{ACKNOWLEDGMENTS}

CAPES - Coordenação de Aperfeiçoamento de Pessoal de Nível Superior, LaMEM - USP - Universidade de São Paulo, for by test support.

Amata Brasil and to Eng. Marcelo Germani, for help in the manufacture of the eucalyptus panel.

Mr. Jerse da Silva of Serraria Ibaiti, and the companies Akzo Nobel for help in the manufacture of the pine panel.

\section{BIBLIOGRAPHY}

[1] CRESPELl, P., GAGNON, S., Cross Laminated Timber: a Primer, In: Report Special Publication 52, FPInnovations, Pointe-Claire, QC, 2010.

[2] TRADA Technology. Case Study: Stadthaus, 24 Murray Grove, London, 1-7. TRADA Technology Ltd., 
U.K., 2009.

[3] BRANDNER, R., et. al, “Cross laminated timber (CLT): overview and development”, European Journal of Wood and Wood Products, v. 74, n. 3, pp. 331-351, Jan. 2016.

[4] LEHMANN, S., "Sustainable Construction for Urban Infill Development Using Engineered Massive Wood Panel Systems”, Sustainability Journal, v. 4, n. 10, pp. 2707-2742, 2012.

[5] SANTONI, A., et. al., "Determination of the elastic and stiffness characteristics of cross-laminated timber plates from flexural wave velocity measurements", Journal of Sound and Vibration, v. 400, pp. 387-401, 2017.

[6] MAHALLE, L., O’CONNOR, J., BARRY, A. "Environmental performance of cross-laminated timber". In: Gagnon, S., Pirvu, C. (eds), “CLT handbook: Cross-laminated timber", v.1, Chapter 11, Canadian ed. Québec, QC: FPInnovations, 2011.

[7] CHRISTOVASILIS, I., et al., Evaluation of the mechanical properties of cross laminated timber with elementary beam theories, "Construction and Building Materials", v.122, pp. 202-213, 2016.

[8] AUGUSTIN, M. “Structural Timber”. In: Tentis (eds), “Handbook 1: Timber Structures”. v.1, ed. 1, Chapter 3, Graz, AU, Leonardo da Vinci Pilot Project, 2008.

[9] KREUZINGER, H., "Mechanically jointed members and CLT elements". In: Blaß, H. J, Sandhaas, C.(eds), “Timber Engineering - Principles for design”. v.1, Chapter 7, Karlsruhe, DE, Karlsruher Institut für Technologie (KIT) Scientific Publishing, 2017.

[10] EN 1995-1-1, Eurocode 5: Design of timber structures - Part 1-1: General - Common rules and rules for buildings, 2004.

[11] GAGNON, S., POPOVSKI, M., "Structural design of cross-laminated timber elements", In: Gagnon, S., Pirvu, C. (eds), “CLT handbook: Cross-laminated timber”. v.1, Chapter 11, Canadian ed. Québec, QC: FPInnovations, 2011.

[12] ANSI/APA PRG 320, Standard for Performance-Rated Cross-Laminated Timber, 2011.

[13] EN 16351, Timber structures. Cross laminated timber. Requirements, 2015.

[14] BLAß, H. J, SANDHAAS, C., "Timber Engineering - Principles for design”. 2 ed., Karlsruhe, DE, Karlsruher Institut für Technologie (KIT) Scientific Publishing, 2017.

[15] NBR 6120, Cargas para o cálculo de estruturas de edificações, 1980.

[16] CALIL NETO, C, et. al, "Madeira Laminada Colada no Brasil: Situação Atual e Perspectivas". In: $X V$ EBRAMEM - Encontro Brasileiro em Madeiras e em Estruturas de Madeira, Curitiba, 2016.

[17] BOLETIM SNIF, “Sistema Nacional de Informações Florestais”, v.1, ed. 2, Brasília, MMA, 2016.

[18] KLH, Technical Catalogue for Engineering, KLH Massivholz Gmbh, 2008.

\section{ORCID}

Marcos Cesar de Moraes Pereira https://orcid.org/0000-0002-7058-8538

Carlito Calil Jr.

https://orcid.org/0000-0001-6037-2816 